\title{
Severe Valvular Regurgitation: An Unexpected Complication During Transapical Aortic Valve Implantation Treated Successfully with the "Valve-in-Valve" Procedure
}

\author{
Kamil Mehmet Burgazlı1-2, Ethem Kavukcu², Ridvan Chasan', Mehmet Bilgin ${ }^{3}$, Ali Erdoğan \\ ${ }^{1}$ Department of Cardiology and Angiology, JL-University of Giessen, Giessen, Germany \\ ${ }^{2}$ Department of Internal Medicine and Angiology, Medical and Research Center Wuppertal, Wuppertal, Germany \\ ${ }^{3}$ Department of Radiology, Faculty of Medicine, Bezmialem Vakıf University, Istanbul, Turkey
}

\begin{abstract}
Severe symptomatic aortic stenosis (AS) in a multimorbid 77 year old female was treated with transapical aortic valve implantation with a 23 mm Edwards Sapien valve. Severe valvular regurgitation following implantation, probably due to structural valve failure, was treated successfully with a second valve-invalve implantation. During a follow-up time of 2,5 years no further problems occurred.
\end{abstract}

Key Words: TAVI, aortic regurgitation, complication

Received: 10.04.2012 Accepted: 28.05.2012

\section{Introduction}

In percutaneous aortic valve replacement or Transcatheter Aortic Valve Implantation (TAVI), a replacement cow heart valve is passed through a hole in the groin by a puncture of the femoral artery and advanced up to the ascending aorta of the patient. It substitutes for a more invasive procedure in which the chest is opened in patients with high surgical or anesthetic risk.

Patients with a high surgical risk transcatheter aortic valve implantation (TAVI) have become an accepted alternative to surgical valve implantation with a comparable outcome $(1,2)$. The catheter procedure was developed in Europe, being initially performed in 2002 in France (3). It is effective in improving functioning in patients with severe aortic stenosis.

In high-risk patients with severe aortic stenosis, transcatheter and surgical procedures for aortic-valve replacement had similar rates of survival at 1 year, although there were important differences in risks associated with the procedure. The first TAVI was performed by Alain Cribier (3), and subsequently thousands of TAVIs have followed. Since then many serious complications associated with TAVI like paravalvular aortic regurgitation, malposition including valve migration and procedure related complications have been described in the literature (4-7). We report a case of acute structural valve failure causing severe central regurgitation, which was treated with a valve-in-valve procedure.

\section{Case Report}

A multimorbid 77-year old female patient was referred to our center with severe symptomatic aortic stenosis (AS). She had a history of systemic lupus erythematosis, antiphospholipid syndrome and hepatic cirrhosis combined with ascites. Echocardiography confirmed severe AS with a valve area of $0.6 \mathrm{~cm}^{2}$ and gradient of $108 / 73 \mathrm{mmHg}$. Left ventricular valve function was preserved (EF 61\%) with increased wall thickness (IVS $15 \mathrm{~mm}$, posterior wall $14 \mathrm{~mm}$ ). Furthermore, an aortic insufficiency grade $\mathrm{I}^{\circ}$ and a mitral insufficiency grade $1 \mathrm{II}^{\circ}$ could be shown (Figure 1A). The patient was ranked as unsuitable for a surgical aortic valve implantation because of comorbidities and an Euroscore of 20 . So, the patient was considered for TAVI and because of peripheral arterial disease we decided for a transapical procedure.

The procedure was performed under general anaesthesia and TEE guidance in the catheter lab (hybrid operating room) by a team of cardiologists and cardiac surgeons. An anterior left mini-thoracotomy was performed to obtain access to the apex of the left ventricle. After the puncture of the apex, a stiff guide wire was positioned through the aortic valve in the descending aorta. A 22-F-sheath was inserted in the left ventricle and the aortic valve deployment was performed during rapid pacing (Figure 1B). After implantation of a $23 \mathrm{~mm} \mathrm{Sa-}$ pien Edwards valve the gradient disappeared. Unfortunately, a severe leak in the valve was observed (Figure 1C). After se- 


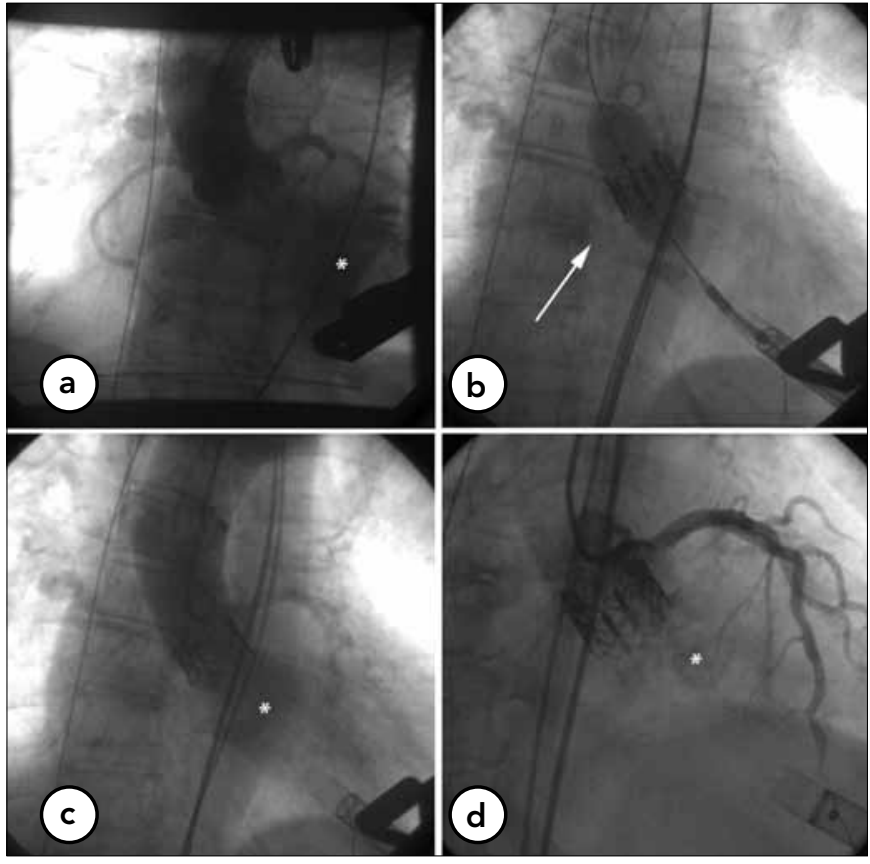

Figure 1. Fluoroscopic views (left anterior descendent, LAO $\left.30^{\circ}\right)$. A-D: see explanation a) Coronarangiography with severe aortic stenosis and aortic insufficiency grade $I^{\circ}$ before TAVI (white star shows regurgitating contrast medium) b) Transapical Edwards-Sapien Valve during implantation (see white arrow) c) First control coronarangiography after first valve implantation showed a severe leak in the valve with severe regurgitation (see white star) d) Second control coronarangiography after valve-in-valve implantation with very little regurgitation (see white star)

veral failed attempts with a "pig-tail" catheter to "open" the valve and twenty minutes of "wait and see", we decided to dilate the valve for a second time but this was also unsuccessful. The team decided to carry out a valve in valve procedure and another valve of the same size ( $23 \mathrm{~mm}$ diameter) was implanted. After re-implantation, the insufficiency disappeared (Figure 1D). The postoperative period was uneventful and the patient was discharged at day 9.

After a follow-up of 4 weeks, echocardiography showed a normal function of the aortic valve with a mean gradient of 8 $\mathrm{mmHg}$ and without insufficiency (Figure 2).

In the meantime, a follow up time of 2.5 years was reached without any further problems.

\section{Discussion}

Currently, the TAVI procedure is the only alternative for patients with severe symptomatic aortic stenosis who have a high surgical risk and cannot be considered for open heart surgery. Both the Core-valve and Edwards Sapien valve are associated with several procedure related complications. In addition to access site related and systemic complications (sepsis, stroke, tamponade), improper positioning of the valve can also lead to life-threatening complications such as device embolization causing significant paravalvular or valvular regurgitation or even coronary obstruction, permanent heart

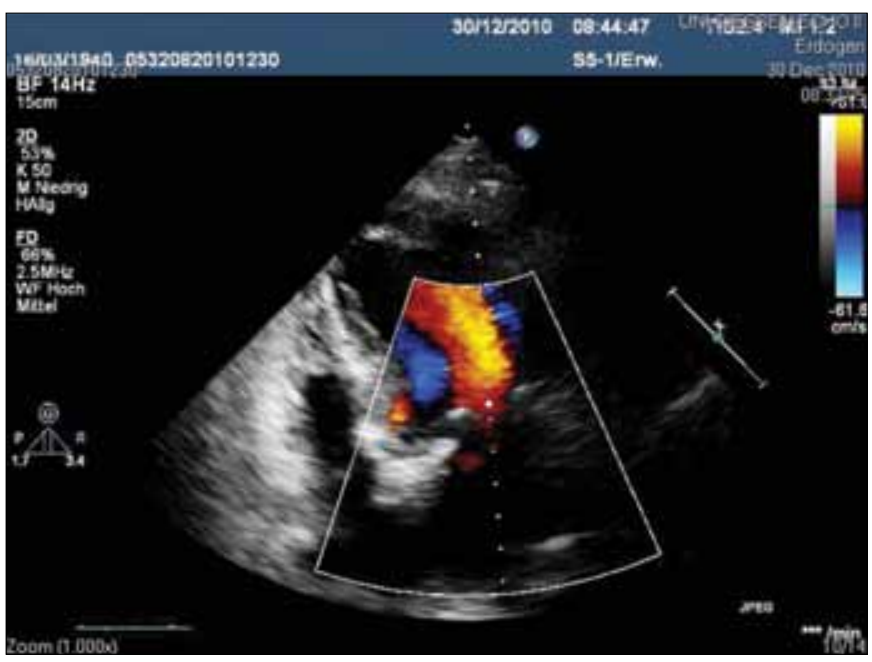

Figure 2. Echocardiography showed the aortic valve with a mean gradient of $8 \mathrm{mmHg}$ and without insufficiency

block or mitral valve injury $(2,8)$. The differences in the rate of complications are related to the anatomic design of the valve (Edwards or CoreValve). Otherwise, paravalvular or intravalvular leakage is theoretically possible for both principles of implantation. The mechanism of successful TAVI involves pushing the native valve against the aortic annulus and wall. Due to the distribution of calcium this occurs unevenly, leading to small areas of paravalvular leak, most of which have little clinical significance. However, paravalvular leak can be significant necessitating the implantation of a second valve (9). A recent study with Core valve by Sherif et al. (10) showed that the probability of significant aortic regurgitation rose as the angle of the axis of the left ventricular outflow tract to the axis of the ascending aorta increased. In this study, regurgitation risk was lowest when the device was implanted at a depth of $10 \mathrm{~mm}$ below the noncoronary cusp. In rare cases acute regurgitation may result from pressure on a bioprosthesis cusp by a guidewire as reported by Al-Attar et al. (11). As mentioned above, several catheter manipulations were unsuccessful in our case so that we believe the valvular insufficiency was due to structural valve failure and not to improper positioning as the regurgitation disappeared after the implantation of a second valve in the same position.

In our opinion, TAVI will become a standard procedure in the next decade. The good results of TAVI procedure compared with standard conventional surgery procedure (20\% better 1 year survival) published in 2010 encourage expansion of the indication (12).

\section{Conclusion}

Valve-in valve procedure with the same or a different system may be a life saving option in the setting of acute valvular or paravalvular regurgitation during percutaneous or transapical TAVI procedure.

\section{Conflict of Interest}

No conflict of interest was declared by the authors. 


\section{References}

1. Webb JG, Pasupati S, Humphries K, Thompson C, Altwegg L, Moss $R$, et al. Percutaneous transarterial aortic valve replacement in selected high risk patients with aortic stenosis. Circulation 2007; 116:755-63. [CrossRef]

2. Walther T, Simon P, Dewey T, Wimmer-Greinecker G, Falk V, Kasimir MT, et al. Transapical minimally invasive aortic valve implantation: multicenter experience. Circulation 2007;116:240-5. [CrossRef]

3. Cribier A, Eltchaninoff H, Bash A, Borenstein N, Tron C, Bauer F, et al. Percutaneous transcatheter implantation of an aortic valve prosthesis for calcific aortic stenosis: first human case description. Circulation 2002;106:3006-8. [CrossRef]

4. Ducrocq G, Francis F, Serfaty JM, Himbert D, Maury JM, Pasi N, et al. Vascular complications of transfemoral aortic valve implantation with the Edwards SAPIEN prosthesis: incidence and impact on outcome. Eurolntervention 2010;5:666-72. [CrossRef]

5. Van Mieghem NM, Nuis RJ, Piazza N, Apostolos T, Ligthart J, Schultz $C$, et al. Vascular complications with transcatheter aortic valve implantation using the $18 \mathrm{Fr}$ Medtronic Core Valve System: the Rotterdam experience. Eurolntervention 2010;5:673-9. [CrossRef]

6. Sinhal A, Altwegg L, Pasupati S, Humphries KH, Allard M, Martin $\mathrm{P}$, et al. Atrioventricular block after transcatheter balloon ex- pand- able aortic valve implantation. JACC Cardiovasc Interv 2008;1:305-9. [CrossRef]

7. Masson JB, Kovac J, Schuler G, Ye J, Cheung A, Kapadia S, et al. Transcatheter aortic valve implantation: review of the nature, management, and avoidance of procedural complications. JACC Cardiovasc Interv 2009;2:811-20. [CrossRef]

8. Grube E, Schuler G, Buellesfeld L, Gerckens U, Linke A, Wenaweser $P$, et al. Percutaneous aortic valve replacement for severe aortic stenosis in high-risk patients using the second- and current third-generation self-expanding CoreValve prosthesis: device success and 30day clinical outcome. J Am Coll Cardiol 2007;50:69-76. [CrossRef]

9. Rodes-Cabau J, Dumont E, Doyle D. Valve in valve for the treatment of paravalvular leaks following transcatheter aortic valve implantation. Catheter Cardiovasc Interv 2009;74:1116-9. [CrossRef]

10. Sherif MA, Abdel-Wahab M, Stöcker B, Geist V, Richardt D, Tölg $\mathrm{R}$, et al. Anatomic and procedural predictors of paravalvular aortic regurgitation after implantation of the Medtronic CoreValve bioprosthesis. J Am Coll Cardiol 2010;56:1623-9. [CrossRef]

11. Al-Attar N, Ghodbane W, Himbert D, Rau C, Raffoul R, Messikazeitoun $\mathrm{D}$, et al. Unexpected complications of transapical aortic valve implantation. Ann Thorac Surg 2009;88:90-4. [CrossRef]

12. Schaff HV. Transcatheter aortic-valve implantation--at what price? N Engl J Med 2011;364:2256-8. 